\title{
Ultrastructure of the spermatozoon of the trematode Notocotylus noyeri (Digenea: Notocotylidae), a parasite of Microtus arvalis (Rodentia: Cricetidae)
}

\author{
Papa Ibnou Ndiaye ${ }^{1}$, Jordi Torres ${ }^{2,3}$, Catarina Eira ${ }^{4,5}$, Vladimir V. Shimalov ${ }^{6}$ and Jordi Miquel , $^{2,3}$ \\ ${ }^{1}$ Laboratory of Evolutionary Biology, Ecology and Management of Ecosystems, Faculty of Sciences and Techniques, Cheikh Anta \\ Diop University of Dakar, Dakar, Senegal; \\ ${ }^{2}$ Laboratori de Parasitologia, Departament de Microbiologia i Parasitologia Sanitàries, Facultat de Farmàcia, Universitat de \\ Barcelona, Barcelona, Spain; \\ ${ }^{3}$ Institut de Recerca de la Biodiversitat, Facultat de Biologia, Universitat de Barcelona, Barcelona, Spain; \\ ${ }^{4}$ CESAM \& Departamento de Biologia, Universidade de Aveiro, Aveiro, Portugal; \\ ${ }^{5}$ Sociedade Portuguesa de Vida Selvagem, Estaçao de Campo de Quiaios, Figueira da Foz, Portugal; \\ ${ }^{6}$ Brest State University, Brest, Belarus
}

\begin{abstract}
In the present paper, we describe the ultrastructure of the spermatozoon of the notocotylid Notocotylus noyeri (Joyeux, 1922) by means of transmission electron microscopy. The mature spermatozoon of $N$. noyeri exhibits the general pattern described in the majority of digeneans: two axonemes of the $9+$ " 1 " pattern of the Trepaxonemata, nucleus, mitochondria, parallel cortical microtubules, spine-like bodies and ornamentation of the plasma membrane. The glycogenic nature of the electron-dense granules was evidenced applying the test of Thiéry. The ultrastructural features of the spermatozoon of $N$. noyeri present some differences in relation to those of the Pronocephalidea described until now, but confirm a general pattern for the Notocotylidae, namely a spermatozoon with two mitochondria and an anterior region with ornamentation of the plasma membrane associated with spine-like bodies. The posterior extremity of the spermatozoon exhibits only some microtubules after the disorganisation of the second axoneme. The present study confirms that some ultrastructural characters of the sperm cell such as the presence or absence of lateral expansions, the number of mitochondria and the morphology of both anterior and posterior spermatozoon extremities are useful for phylogenetic purposes within the Pronocephaloidea. Thus, unlike notocotylids, pronocephalids exhibit external ornamentation and a lateral expansion in the anterior spermatozoon region. Moreover, notocotylid spermatozoa present two mitochondria, whereas pronocephalid spermatozoa exhibit a single mitochondrion. Finally, pronocephalids are characterised by a type 2 posterior spermatozoon extremity, whereas notocotylids exhibit a type 3 posterior spermatozoon extremity.
\end{abstract}

Keywords: Platyhelminthes, Pronocephaloidea, sperm characters, cytochemistry, TEM

The cosmopolitan digenean genus Notocotylus Diesing, 1839 includes more than forty species of intestinal flukes that are mainly parasites of aquatic birds, but also mammals (rodents and chiropterans), all dwelling in wetland habitats because of their life cycle that involves aquatic gastropods (Barton and Blair 2005a, Kinsella and Tkach 2005, Chaisiri et al. 2011). The genus Notocotylus as a member of the family Notocotylidae Lühe, 1909 belongs to the superfamily Pronocephaloidea Looss, 1899, which has been a subject of many controversies from a systematic point of view (see Barton and Blair 2005b). According to these authors, there are six families recognised within the Pronocephaloidea: Pronocephalidae Looss, 1899, Notocotylidae Lühe, 1909, Nudacotylidae Barker, 1916, Opisthotremati- dae Poche, 1926, Rhabdiopoeidae Poche, 1926 and Labicolidae Blair, 1979.

Over the last decades, there has been an important increase in the number of ultrastructural studies on spermiogenesis and/or on the spermatozoon of digeneans (Bakhoum et al. 2013, Miquel et al. 2013, Ndiaye et al. 2013). Moreover, there have been important efforts to clarify the usefulness of spermiological characters in digeneans in the near future, especially since sperm models were already established for cestodes (Levron et al. 2010). Until now, the ultrastructural and spermiological knowledge on the Pronocephaloidea was restricted to three species belonging to two families: the notocotylid Notocotylus neyrai González Castro, 1945 and the pronocephalids Cricocephalus albus

Address for correspondence: J. Miquel, Laboratori de Parasitologia, Departament de Microbiologia i Parasitologia Sanitàries, Facultat de Farmàcia, Universitat de Barcelona, Av. Joan XXII, s/n, E-08028 Barcelona, Spain. Phone: +34 93 4024500; Fax: +34 93 4024504; E-mail: jordimiquel@ub.edu 

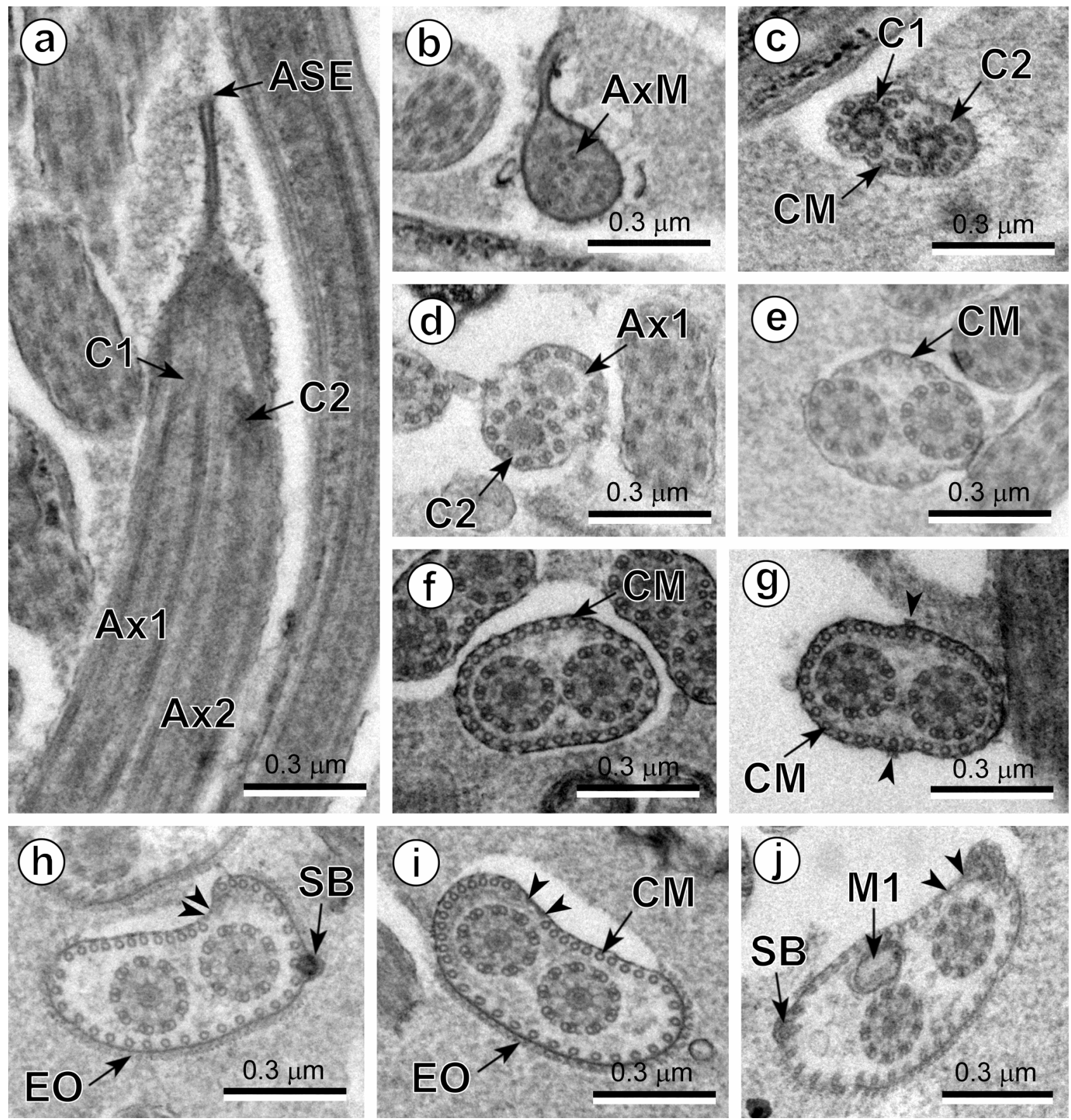

Fig. 1. Mature spermatozoon of Notocotylus noyeri (Joyeux, 1922) from Microtus arvalis. a-longitudinal section of anterior extremity of the spermatozoon showing the two centrioles; $\mathbf{b}$ - cross-section of the anterior extremity of spermatozoon showing microtubules of future axoneme; $\mathbf{c}-\mathbf{e}$ - consecutive cross-sections showing appearance of the axonemes; $\mathbf{f}, \mathbf{g}$ - cross-sections showing continuous layer of cortical microtubules and appearance of external ornamentation of plasma membrane (arrowheads); $\mathbf{h}-\mathbf{j}$ - cross-section of ornamented region with spine-like bodies and first mitochondrion. Note the presence of two attachment points (arrowheads). Abbreviations: ASE - anterior spermatozoon extremity; Ax1 - first axoneme; Ax2 - second axoneme; AxM - axonemal microtubules; C1 - centriole of the first axoneme; $\mathrm{C} 2$ - centriole of the second axoneme; $\mathrm{CM}$ - cortical microtubules; EO - external ornamentation of plasma membrane; M1 - first mitochondrion; SB - spine-like bodies.

(Kuhl et van Hasselt, 1822) and Pleurogonius truncatus Prudhoe, 1944 (see Ndiaye et al. 2003, 2011, 2012).

The aim of the present study is to describe the ultrastructure of the spermatozoon of a second species of the genus Notocotylus, N. noyeri (Joyeux, 1922), and to compare its ultrastructural organisation with those of other digeneans, particularly pronocephaloideans.

\section{MATERIALS AND METHODS}

Live specimens of Notocotylus noyeri were collected from the intestine of a naturally infected Microtus arvalis (Pallas). Voles were captured by V.V. Shimalov in the Bugskiy landscape reserve (Southwest Belarus).

After their extraction, adult worms were immediately rinsed with a $0.9 \% \mathrm{NaCl}$ solution and fixed in cold $\left(4^{\circ} \mathrm{C}\right) 2.5 \%$ glutaral- 

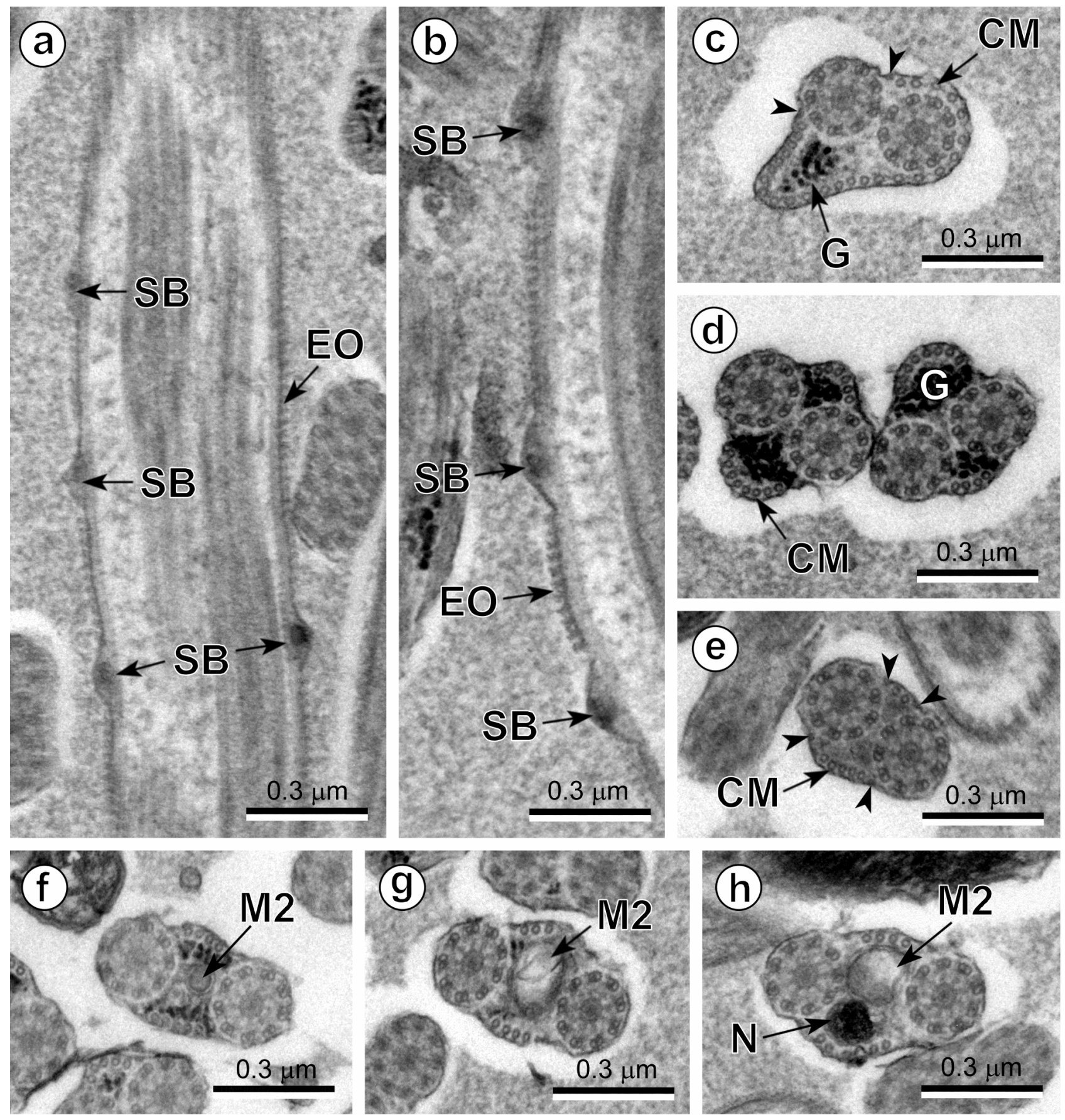

Fig. 2. Mature spermatozoon of Notocotylus noyeri (Joyeux, 1922) from Microtus arvalis. a-b - longitudinal sections of ornamented area of sperm showing details of spine-like bodies; $\mathbf{c}-\mathbf{g}$-cross-sections in region II of spermatozoon showing the two axonemes, cortical microtubules, granules of glycogen, and two attachment points in c and four attachment points in e (arrowheads). Note the progressive reduction of the cortical microtubules disposed in two bundles and the apparition of the second mitochondrion in the posterior part of this region; $\mathbf{h}$ - cross-section in the anterior part of region III showing the simultaneous presence of the nucleus and second mitochondrion. Abbreviations: CM - cortical microtubules; EO - external ornamentation of the plasma membrane; $\mathrm{G}$ - granules of glycogen; M2 - second mitochondrion; N - nucleus; SB - spine-like bodies.

dehyde in a $0.1 \mathrm{M}$ sodium cacodylate buffer at $\mathrm{pH} 7.4$ for a minimum of $2 \mathrm{~h}$, rinsed in $0.1 \mathrm{M}$ sodium cacodylate buffer at $\mathrm{pH} 7.4$, post-fixed in cold $\left(4^{\circ} \mathrm{C}\right) 1 \%$ osmium tetroxide with $0.9 \%$ potassium ferricyanide $\left[\mathrm{K}_{3} \mathrm{Fe}(\mathrm{CN})_{6}\right]$ in the same buffer for $1 \mathrm{~h}$, rinsed in milliQ water, dehydrated in an ethanol series and propylene oxide, embedded in Spurr's resin and polymerised at $60^{\circ} \mathrm{C}$ for $72 \mathrm{~h}$.

Ultrathin sections (60-90 nm thick) of specimens at the level of the internal seminal vesicle were obtained in a Reichert-Jung
Ultracut E ultramicrotome using a diamond knife. Sections were placed on copper and gold $200 \mu \mathrm{m}$ mesh grids. Sections placed on copper grids were double-stained with uranyl acetate and lead citrate according to the Reynolds (1963) procedure. Sections placed on gold grids were treated according to the Thiéry (1967) test to reveal the presence of glycogen. Thus, they were treated in periodic acid (PA), thiocarbohydrazide $(\mathrm{TCH})$ and silver proteinate (SP) as follows: $30 \mathrm{~min}$ in $10 \% \mathrm{PA}$, rinsed in milliQ water; $24 \mathrm{~h}$ 
Table 1. Spermatological characters in the superfamily Pronocephaloidea.

\begin{tabular}{|c|c|c|c|c|c|c|c|c|c|}
\hline \multirow{2}{*}{$\begin{array}{l}\text { Families and species } \\
\text { References }\end{array}$} & \multicolumn{9}{|c|}{ Spermatological characters } \\
\hline & ASE & $\mathrm{EO}^{1}$ & $\mathrm{EO}^{2}$ & LE & SB & $\mathrm{M}$ & G & PSE & Type $^{3}$ \\
\hline \multicolumn{10}{|l|}{ Notocotylidae } \\
\hline $\begin{array}{l}\text { Notocotylus neyrai } \\
\text { Ndiaye et al. (2003) }\end{array}$ & $1 \mathrm{Ax} ?$ & - & + & - & + & 2 & + & Ax & 3 \\
\hline $\begin{array}{l}\text { Notocotylus noyeri } \\
\text { Present study }\end{array}$ & $2 \mathrm{Ax}$ & - & + & - & + & 2 & + & Ax & 3 \\
\hline \multicolumn{10}{|l|}{ Pronocephalidae } \\
\hline $\begin{array}{l}\text { Cricocephalus albus } \\
\text { Ndiaye et al. (2011) }\end{array}$ & DM-EO-CM & + & + & + & + & 1 & + & $\mathrm{N}$ & 2 \\
\hline $\begin{array}{l}\text { Pleurogonius truncatus } \\
\text { Ndiaye et al. (2012) }\end{array}$ & EO-CM & + & + & + & + & 1 & + & $\mathrm{N}$ & 2 \\
\hline
\end{tabular}

Abbreviations: ASE - anterior spermatozoon extremity; Ax - axoneme; CM - cortical microtubules; DM - electron-dense material; EO - external ornamentation of plasma membrane; $\mathrm{G}$ - granules of glycogen; LE - lateral expansion; $\mathrm{M}$ - number of mitochondria; $\mathrm{N}$ - nucleus; PSE - posterior spermatozoon extremity; SB - spine-like body; ${ }^{1}$ external ornamentation located in the anterior spermatozoon tip; ${ }^{2}$ external ornamentation located in the middle spermatozoon area; ${ }^{3}$ Quilichini et al. (2010)'s types of digenean posterior spermatozoon extremities.
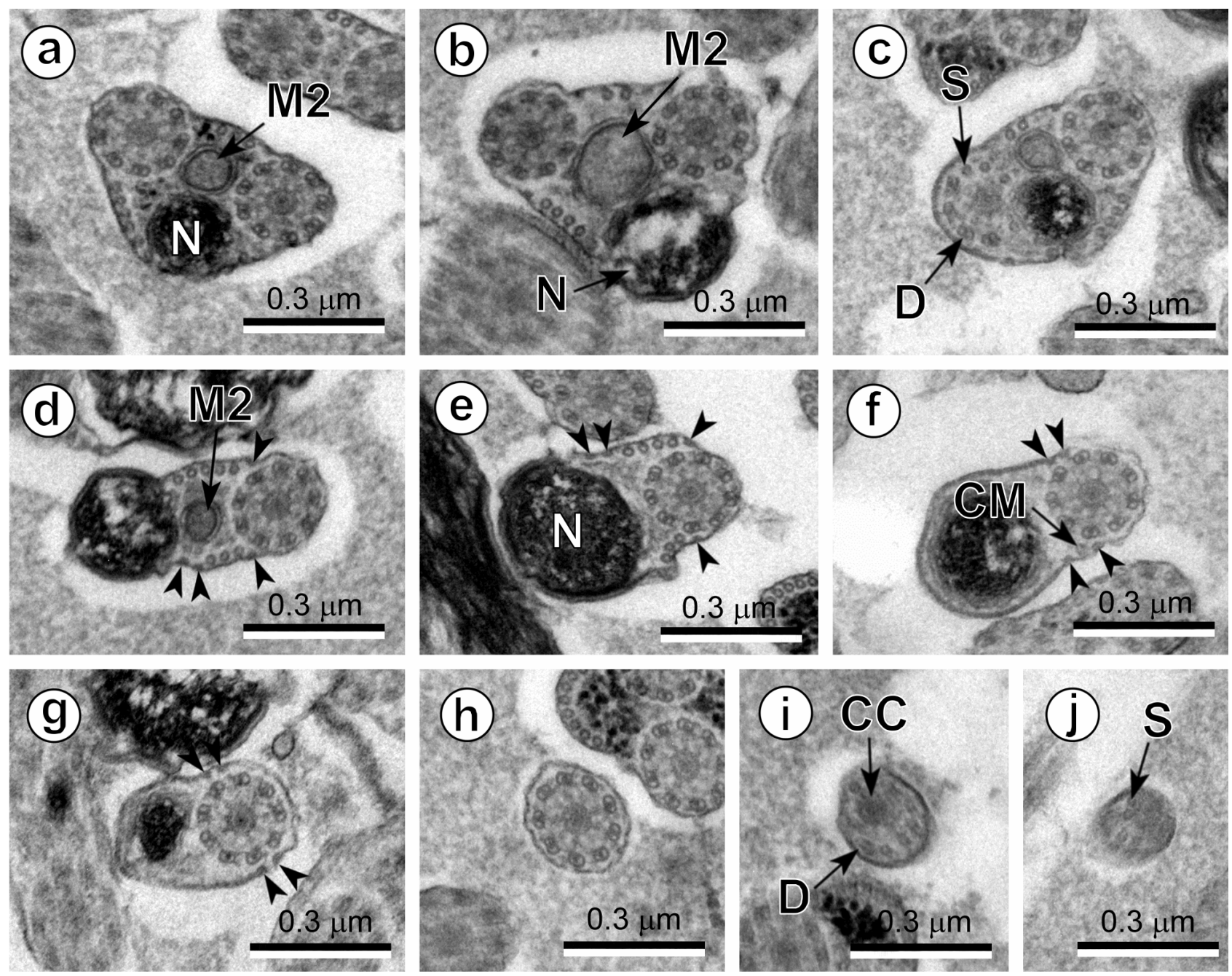

Fig. 3. Mature spermatozoon of Notocotylus noyeri (Joyeux, 1922) from Microtus arvalis. a-g - consecutive cross-sections of region III showing disorganisation of the first axoneme in c, stopping of the second mitochondrion in e and reduction of nuclear size until its disappearance in $\mathrm{g}$. Arrowheads in $\mathrm{d}-\mathrm{g}$ indicate the attachment points; $\mathbf{h}-\mathbf{j}$-cross-sections of the posterior spermatozoon tip showing disorganisation of the second axoneme. Abbreviations: CC - central core; CM - cortical microtubules; D - doublets; M2 - second mitochondrion; $\mathrm{N}$ - nucleus; $\mathrm{S}$ - singlets.

in $\mathrm{TCH}$, rinsed in acetic solutions and milliQ water; and $30 \mathrm{~min}$ in $1 \% \mathrm{SP}$ in the dark, rinsed in milliQ water.
The grids were examined in a JEOL 1010 transmission electron microscope operated at $80 \mathrm{kV}$, in the Centres Científics i Tecnològics de la Universitat de Barcelona (CCiTUB). 


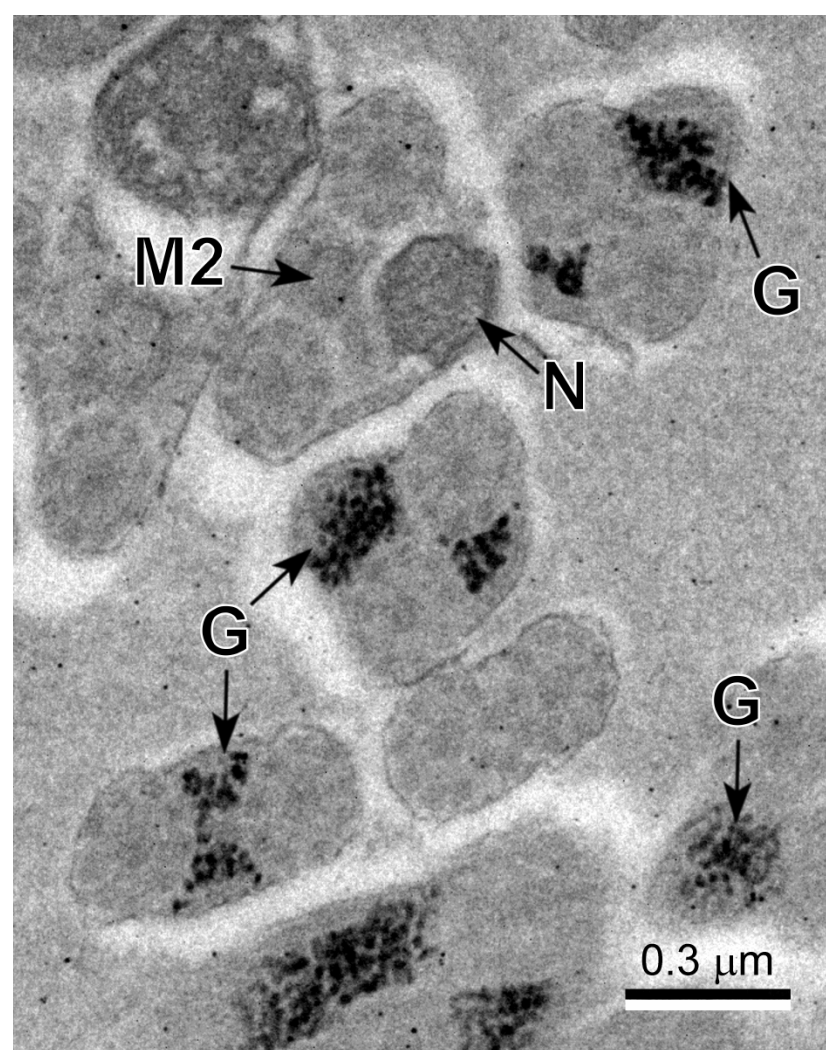

Fig. 4. TEM micrograph showing the positive results of test of Thiéry. Abbreviations: G - granules of glycogen; M2 - second mitochondrion; $\mathrm{N}$ - nucleus.

\section{RESULTS}

The observation of numerous cross and longitudinal sections of the mature spermatozoon of Notocotylus noyeri allowed us to distinguish three regions from the anterior to the posterior extremities of the spermatozoon.

Region I (Figs. 1a-j, 2a,b and 5I) corresponds to the anterior region of the spermatozoon. It is characterised by the presence of two axonemes $(\mathrm{Ax} 1, \mathrm{Ax} 2)$ and cortical microtubules $(\mathrm{CM})$ in the anterior part and spine-like bodies (SB), external ornamentation (EO) of the plasma membrane and the first mitochondrion (M1) in the posterior part. A longitudinal section in the anterior extremity of the spermatozoon (Fig. 1a) shows a slight longitudinal displacement between the centrioles $\mathrm{C} 1$ and $\mathrm{C} 2$. However, the observation of the centrioles at the same level in a cross-section (Fig. 1c) allows us to consider the presence of two axonemes as a characteristic of the anterior spermatozoon extremity (see Table 1). Consecutive cross-sections of region I show the singlets of axonemes (AxM) (Fig. 1b) successively turning into doublets of the centrioles $\mathrm{C} 1$ and C2 (Fig. 1c), which will then become axonemes Ax1 and Ax2 (Fig. 1d,e). The anterior tip of the spermatozoon is devoid of cortical microtubules (Fig. 1a,b). The cortical microtubules appear right posterior to the tip (Fig. 1c-e) and increase in number to form a complete layer of cortical microtubules under the plasma membrane (Fig. 1 f,g). In posterior areas of region I the layer of submembraneous cortical microtubules becomes discontinuous showing two electron-dense marks that correspond to the attachment zones (Fig. 1h-j). This posterior area of region I also exhibits the external ornamentation of the plasma membrane (EO), the spine-like bodies (SB) and the first mitochondrion (M1) (Figs. 1h-j, 2a,b).

Region II (Figs. 2c-g and 5II) corresponds to the middle region of the spermatozoon. It is characterised by the disappearance of the external ornamentation of the plasma membrane, spine-like bodies and the first mitochondrion. Thus, cross-sections of the anterior areas of region II show only two axonemes, granules of glycogen (G) (Fig. 2c) and reorganisation of the submembraneous layer of cortical microtubules in two reduced bundles placed in the ventral and dorsal sides of the spermatozoon (Fig. 2d,e). The posterior area of region II is characterised by the appearance of the second mitochondrion (M2) in addition to the already described structures (two axonemes, cortical microtubules, granules of glycogen and four attachment zones).

Region III (Figs. 2h, 3a-j and 5III) corresponds to the posterior region of the spermatozoon. It is characterised by the simultaneous presence of the nucleus $(\mathrm{N})$ and the second mitochondrion (M2) in addition to the structures described in the posterior part of region II (Figs. 2h, 3a,b). Toward the posterior spermatozoon tip, consecutive crosssections show the disorganisation and disappearance of the first axoneme (Fig. 3c,d), then the second mitochondrion (Fig. 3e), progressive disappearance of cortical microtubules (Fig. 3e-g) and finally the nucleus (Fig 3h). Thus, the posterior extremity of the spermatozoon is characterised by the presence of only the second axoneme (Fig. 3h) that progressively disorganises showing the central core (CC), doublets (D) and singlets (S) (Fig. 3i,j).

The glycogenic nature of the electron-dense granules was evidenced applying the test of Thiéry (Fig. 4).

\section{DISCUSSION}

In the superfamily Pronocephaloidea, the ultrastructural organisation of the spermatozoon is known for four species belonging to two of the six families that constitute this superfamily (see Barton and Blair 2005b). These species are the notocotylids Notocotylus neyrai and N. noyeri, and two pronocephalids Cricocephalus albus and Pleurogonius truncatus (see Ndiaye et al. 2003, 2011, 2012; present study).

The mature spermatozoon of $N$. noyeri shows an ultrastructural organisation with numerous characters described in most digeneans: the presence of two axonemes of the $9+$ " 1 " type of the Trepaxonemata (Ehlers 1984), mitochondrion, nucleus and parallel cortical microtubules (Miquel et al. 2006, Quilichini et al. 2010, Bakhoum et al. 2013, Ndiaye et al. 2013). Furthermore, additional features are described, which are potentially useful for comparing species belonging the Pronocephaloidea (see Table 1).

With respect to the anterior extremity, the spermatozoa of species of Notocotylus appear to differ in the number of axonemes, namely $N$. neyrai was described as presenting only one axoneme (Ndiaye et al. 2003), whereas $N$. noyeri undoubtedly presents two axonemes (present study). Nevertheless, it is remarkable that longitudinal micrographs in the ultrastructural studies of digenean spermatozoa often 


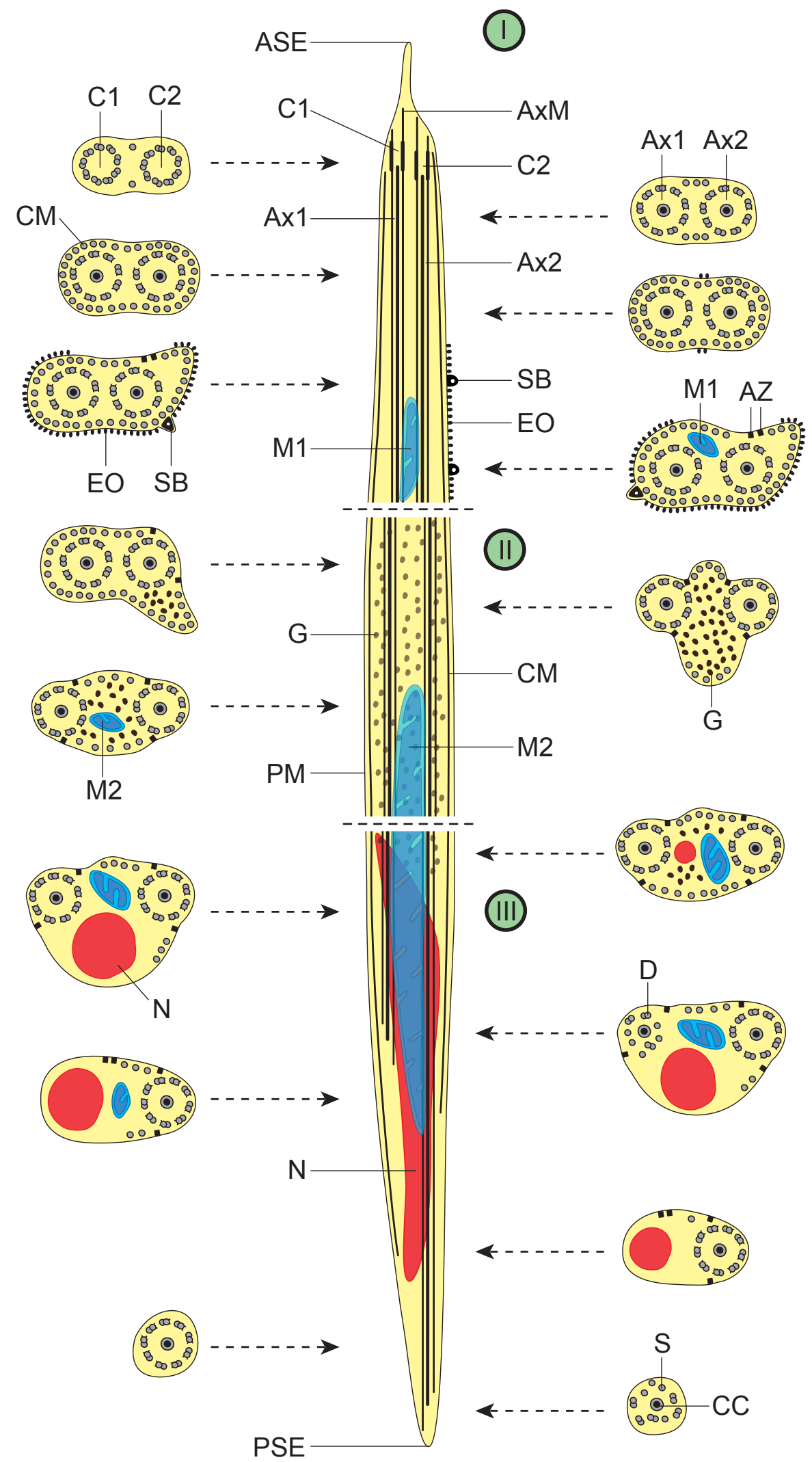

Fig. 5. A schematic reconstruction of the mature spermatozoon of Notocotylus noyeri (Joyeux, 1922) from Microtus arvalis. Abbreviations: ASE - anterior spermatozoon extremity; Ax 1 - first axoneme; Ax 2 -second axoneme; AxM - axonemal microtubules; $\mathrm{AZ}$ - attachment zones, $\mathrm{C} 1$ - centriole of the first axoneme; $\mathrm{C} 2$ - centriole of the second axoneme; $\mathrm{CC}$ - central core; $\mathrm{CM}$ - cortical microtubules; D - doublets; EO - external ornamentation of the plasma membrane; G - granules of glycogen; M1 - first mitochondrion; M2 - second mitochondrion; N - nucleus; PM - plasma membrane; PSE - posterior spermatozoon extremity; S - singlets; SB - spine-like bodies. 
do not provide a complete insight on the characters, e.g. the presence of one or two axonemes. In this sense, the observation of cross-sections showing centrioles is crucial in order to evaluate the presence of one or two axonemes in the anterior spermatozoon extremity. In fact, results on $N$. neyrai concerning the anterior spermatozoon tip must be considered with caution since it is possible that two axonemes are present instead of just the one (Ndiaye et al. 2003).

When members of the superfamily Pronocephaloidea are compared, the most interesting feature at this level of the spermatozoon is the presence of external ornamentation of the plasma membrane associated to an important number of cortical microtubules in pronocephalids (Ndiaye et al. 2011, 2012). Additionally, in C. albus, the anterior extremity also contains an apical electron-dense material (Ndiaye et al. 2011). In contrast, in notocotylids the anterior spermatozoon tip is devoid of external ornamentation of the plasma membrane and these structures are present in more posterior areas of the sperm cell (Ndiaye et al. 2003; present study).

In addition, the presence/absence of a lateral expansion can be a differential character within the Pronocephaloidea, at least for the two examined families. Thus, a lateral expansion is present in the pronocephalids $C$. albus and $P$. truncatus and absent in the notocotylids $N$. neyrai and $N$. noyeri (see Ndiaye et al. 2003, 2011, 2012; present study).

Spine-like bodies associated with the external ornamentation of the plasma membrane have been evidenced in the anterior areas of the spermatozoon of all the Pronocephaloidea studied until now (Ndiaye et al. 2003, 2011, 2012; present study). These structures were described for the first time in the opecoelid Opecoeloides furcatus (Bremser in Rudolphi, 1819) - see Miquel et al. (2000) - and since then, these elements have been found by different authors in the sperm cell of numerous digeneans (for a review see Bakhoum 2012 and Miquel et al. 2013). The function of these structures remains unknown, but like the external ornamentation of the plasma membrane and the lateral expansions, they may play an important role in the process of fertilisation (Justine and Mattei 1982, 1984, 1986, Miquel et al. 2013).
Apart from the differentiating character 'lateral expansion' (present in pronocephalids and absent in notocotylids), the number of mitochondria is also a discriminating character between pronocephalids and notocotylids, each presenting one and two mitochondria, respectively (Ndiaye et al. 2003, 2011, 2012; present study).

Taking into account the three types of posterior extremities of the spermatozoa in the Digenea postulated by Quilichini et al. (2010), other interesting differences in the ultrastructural organisation of male gametes can be distinguished between these two families. Thus, according to the Quilichini's types of posterior spermatozoon extremities, both $N$. noyeri and $N$. neyrai exhibit a posterior extremity of the sperm cell that corresponds to the type 3 or the cryptogonimidean type characterised by the sequence 'cortical microtubules-nucleus-second axoneme' towards the posterior spermatozoon tip. In contrast, the posterior spermatozoon extremity of pronocephalids follows the type 2 ('fasciolidean' type) with the nucleus as a terminal character.

The comparative analysis of the ultrastructural organisation of spermatozoa of $N$. noyeri (present study) and those of $N$. neyrai (Ndiaye et al. 2003) enables us to establish a general model for the genus Notocotylus. Thus, the mature spermatozoon of species of Notocotylus present two axonemes of the $9+$ " 1 " trepaxonematan pattern, two mitochondria (one located in the anterior spermatozoon region and another that occupies both middle and posterior spermatozoon regions), parallel cortical microtubules, granules of glycogen, a nucleus in the posterior region, and spine-like bodies associated with external ornamentation of the plasma membrane in the anterior region. Moreover, the genus Notocotylus exhibits a type 3 ('cryptogonimidean' type) of posterior spermatozoon extremity.

Acknowledgements. The present study was partly funded by a grant from the 'Comissionat per a Universitats i Recerca' (No. 2014 SGR 1241). The authors wish to thank Núria Cortadellas and Almudena García from the 'Unitat de Microscòpia, Facultat de Medicina, Centres Científics i Tecnològics de la Universitat de Barcelona (CCiTUB)' for their support in the preparation of samples. They also thank Online Access to Research in the Environment (OARE) for facilitate them access to the bibliography. CE is supported by PI6421 in MARES (CENTRO-07-ST24FEDER-002033), QREN, Mais Centro - PORC and EU/ERDF.

\section{REFERENCES}

BAKHOUM A.J.S. 2012: Contribution à la connaissance de l'ultrastructure de la spermiogenèse et du spermatozoïde des digènes. PhD Thesis, University of Barcelona, $288 \mathrm{pp}$.

Bakhoum A.J.S., Kacem H., Neifar L., Miquel J. 2013: U1trastructure of the spermatozoon of Centroderma spinosissima (Stossich, 1886) (Digenea: Mesometridae) and its phylogenetic potential. Tissue Cell 45: 428-433.

Barton D.P., Blair D. 2005a: Family Notocotylidae Lühe, 1909. In: A. Jones, R.A. Bray and D.I. Gibson (Eds.), Keys to the Trematoda. Vol. 2. CABI Publishing and Natural History Museum, London, pp. 383-396.

Barton D.P., Blair D. 2005b: Superfamily Pronocephaloidea Looss, 1899. In: A. Jones, R.A. Bray and D.I. Gibson (Eds.), Keys to the Trematoda. Vol. 2. CABI Publishing and Natural History Museum, London, pp. 357-359.
Chaisiri K., Morand S., Ribas A. 2011: Notocotylus loeiensis n. sp. (Trematoda: Notocotylidae) from Rattus losea (Rodentia: Muridae) in Thailand. Parasite 18: 35-38.

Ehlers U. 1984: Phylogenetisches System der Plathelminthes. Verh. Natwiss. Ver. Hamburg, NF, 27: 291-294.

Justine J.-L., Mattei X. 1982: Réinvestigation de l'ultrastructure du spermatozoïde d'Haematoloechus (Trematoda: Haematoloechidae). J. Ultrastr. Res. 81: 322-332.

Justine J.-L., Mattei X. 1984: Ultrastructural observations on the spermatozoon, ovocyte and fertilization process in Gonapodasmius, a gonochoristic Trematode (Trematoda: Digenea: Didymozoidae). Acta Zool. (Stockh.) 65: 171-177.

Justine J.-L., Mattei X. 1986: Ultrastructural observations on fertilization in Dionchus remorae (Platyhelminthes, Monogenea, Dionchidae). Acta Zool. (Stockh.) 67: 97-101. 
Kinsella J.M., TKaCh V.V. 2005: Notocotylus fosteri sp. nov. (Trematoda, Notocotylidae) from the rice rat, Oryzomys palustris in Florida. Acta Parasitol. 50: 194-198.

Levron L., Miquel J., Oros M., Scholz T. 2010: Spermatozoa of tapeworms (Platyhelminthes, Eucestoda): advances in ultrastructural and phylogenetic studies. Biol. Rev. 85: 523-543.

Miquel J., Fournier-Chambrillon C., Fournier P., Torres J. 2006: Spermiogenesis and spermatozoon ultrastructure of the cranial digenean Troglotrema acutum (Leuckart, 1842). J. Parasitol. 92: 441-453.

Miquel J., Nourrisson C., Marchand B. (2000). Ultrastructure of spermiogenesis and the spermatozoon of Opecoeloides furcatus (Trematoda, Digenea, Opecoelidae), a parasite of Mullus barbatus (Pisces, Teleostei). Parasitol. Res. 86: 301-310.

Miquel J., Vilavella D., Swiderski Z., Shimalov V.V., Torres J. 2013: Spermatological characteristics of Pleurogenidae (Digenea) inferred from the ultrastructural study of Pleurogenes claviger, Pleurogenoides medians and Prosotocus confusus. Parasite 20: 28.

Ndiaye P.I., Bakhoum A.J.S., Sène A., Miquel J. 2013: U1trastructure of the spermatozoon of Parahemiurus merus (Linton, 1910) (Digenea: Hemiuroidea: Hemiuridae), a parasite of Sardinella aurita Valenciennes, 1847 and S. maderensis (Lowe, 1838) (Teleostei: Clupeidae) in the Senegalese coast. Zool. Anz. 252: $572-578$.

Ndiaye P.I., Miquel J., Feliu C., Marchand B. 2003: U1trastructure of spermiogenesis and spermatozoa of Notocotylus neyrai González Castro, 1945 (Digenea, Notocotylidae), intestinal parasite of Microtus agrestis (Rodentia: Arvicolidae) in Spain. Invertebr. Reprod. Dev. 43: 105-115.

Ndiaye P.I., Quilichini Y., Sène A., BÂ C.T., Marchand B. 2011: Ultrastructure of the spermatozoon of the digenean Cricocephalus albus (Kuhl \& van Hasselt, 1822) Looss, 1899 (Platyhelminthes, Pronocephaloidea, Pronocephalidae) parasite of the "hawksbill sea turtle" Eretmochelys imbricata (Linnaeus, 1766) in Senegal. Zool. Anz. 250: 215-222.

Ndiaye P.I., Quilichini Y., Sène A., Tkach V.V., BÂ C.T., MARCHAND B. 2012: Ultrastructural study of the male gamete of Pleurogonius truncatus Prudhoe, 1944 (Platyhelminthes, Digenea, Pronocephalidae) parasite of Eretmochelys imbricata (Linnaeus, 1766). C. R. Biol. 335: 239-246.

Quilichini Y., Foata J., Justine J.-L., Bray R.A., Marchand B. 2010: Ultrastructure study of the spermatozoon of Heterolebes maculosus (Digenea, Opistholebetidae), a parasite of the porcupinefish Diodon hystrix (Pisces, Teleostei). Parasitol. Int. 59: 427-434.

REYNOLDS E.S. 1963: The use of lead citrate at high $\mathrm{pH}$ as an electron-opaque stain in electron microscopy. J. Cell Biol. 17: 208-212.

THIÉRY J.P. 1967: Mise en évidence des polysaccharides sur coupes fines en microscopie électronique. J. Microsc. 6: 987-1018.

Cite this article as: Ndiaye P.I., Torres J., Eira C. Shimalov V.V., Miquel J. 2015: Ultrastructure of the spermatozoon of the trematode Notocotylus noyeri (Digenea: Notocotylidae), a parasite of Microtus arvalis (Rodentia: Cricetidae). Folia Parasitol. $62: 001$. 